\title{
Benefits and risks of weight-loss treatment for older, obese women
}

This article was published in the following Dove Press journal:

Clinical Interventions in Aging

8 February 2013

Number of times this article has been viewed

\author{
Lauren M Rossen ${ }^{1,2}$ \\ Vanessa A Milsom ${ }^{1,3}$ \\ Kathryn R Middleton ${ }^{1,4}$ \\ Michael J Daniels ${ }^{5,6}$ \\ Michael G Perri ${ }^{1,7}$ \\ 'Department of Clinical and Health \\ Psychology, University of Florida, \\ Gainesville, FL, USA; ${ }^{2}$ National Center \\ for Health Statistics, Centers for \\ Disease Control and Prevention, \\ Hyattsville, MD, USA; ${ }^{3}$ Department \\ of Psychiatry, Yale University School \\ of Medicine, New Haven, CT, USA; \\ ${ }^{4}$ Weight Control and Diabetes \\ Research Center, Department \\ of Psychiatry and Human Behavior, \\ Warren Alpert Medical School \\ of Brown University and The Miriam \\ Hospital, Providence, RI, USA; \\ ${ }^{5}$ Department of Statistics, University \\ of Florida, Gainesville, FL, USA; \\ ${ }^{6}$ Division of Statistics and Scientific \\ Computation, University of Texas at \\ Austin, Austin, TX, USA; ${ }^{7}$ College of \\ Public Health and Health Professions, \\ University of Florida, Gainesville, \\ FL, USA
}

Correspondence: Michael G Perri College of Public Health and Health Professions, University of Florida, PO Box 100185, Gainesville, FL, 32610-0185, USA

$\mathrm{Tel}+\mathrm{I} 3522736214$

Fax + I 3522736199

Email mperri@phhp.ufl.edu
Background: A key issue in the treatment of obesity in older adults is whether the health benefits of weight loss outweigh the potential risks with respect to musculoskeletal injury.

Objective: To compare change in weight, improvements in metabolic risk factors, and reported musculoskeletal adverse events in middle-aged (50-59 years) and older (65-74 years), obese women.

Materials and methods: Participants completed an initial 6-month lifestyle intervention for weight loss, comprised of weekly group sessions, followed by 12 months of extended care with biweekly contacts. Weight and fasting blood samples were assessed at baseline, month 6 , and month 18; data regarding adverse events were collected throughout the duration of the study.

Results: Both middle-aged $(n=162)$ and older $(n=56)$ women achieved significant weight reductions from baseline to month $6(10.1 \pm 0.68 \mathrm{~kg}$ and $9.3 \pm 0.76 \mathrm{~kg}$, respectively) and maintained a large proportion of their losses at month $18(7.6 \pm 0.87 \mathrm{~kg}$ and $7.6 \pm 1.3 \mathrm{~kg}$, respectively); there were no significant differences between the two groups with respect to weight change. Older women further experienced significant reductions in systolic blood pressure, $\mathrm{HbA}_{1 \mathrm{c}}$, and C-reactive protein from baseline to month 6 and maintained these improvements at month 18. Despite potential safety concerns, we found that older women were no more likely to experience musculoskeletal adverse events during the intervention as compared with their middle-aged counterparts.

Conclusion: These results suggest that older, obese women can experience significant health benefits from lifestyle treatment for obesity, including weight loss and improvements in disease risk factors. Further investigation of the impact of weight loss on additional health-related parameters and risks (eg, body composition, muscular strength, physical functioning, and injuries) in older adults is needed.

Keywords: lifestyle intervention, adverse events, metabolic risk factors

\section{Introduction}

According to reports from the National Health and Nutrition Examination Survey (NHANES), the prevalence of obesity in women 60 to 79 years is $42.3 \%$ (95\% confidence interval [CI]: $38.3 \%-46.3 \%$ ), compared with a prevalence of $31.9 \%$ (95\% CI: $28.6 \%-35.5 \%$ ) in women aged 20 to $39 ;{ }^{1}$ as such, obesity among older women represents a serious public health problem. Obesity in this age group is strongly associated with diabetes, hypertension, dyslipidemia, and osteoarthritis, ${ }^{2}$ although the relation between obesity and all-cause mortality in this age group is inconsistent. ${ }^{3-6}$ Independent of weight status, age is correlated with greater prevalence and severity of many obesity-related health conditions and metabolic risk factors. ${ }^{7}$ Additionally, obesity has been associated with significant impairment in health-related quality of 
life in older individuals. ${ }^{8}$ However, excess weight in older persons ( 65 years and older) may also offer protective benefits with respect to bone loss, osteoporosis, and hip fracture..$^{9,10}$ Further, some have noted the "obesity paradox," whereby obesity has been found to be protective against mortality due to certain causes such as heart failure or cardiovascular disease. ${ }^{11,12}$

For middle-aged and young adults who are obese, the benefits of behavioral weight-loss treatment clearly outweigh potential risks. Reviews of randomized trials demonstrate that lifestyle interventions, typically delivered in weekly group sessions over the course of 4 to 6 months, produce average weight losses of $8.5 \mathrm{~kg}$ posttreatment (approximately $5 \%-10 \%$ of initial body weight). ${ }^{13-15}$ Reductions of this magnitude can have beneficial effects on a variety of weightrelated health conditions and risk factors. ${ }^{16-18}$ However, several longitudinal observational studies have demonstrated that weight loss in older adults is related to increased mortality, disability, functional limitation, institutionalization, loss of lean muscle mass and bone mineral density, increased risk of hip fracture, and loss of mobility. ${ }^{19,20}$ These studies, however, have not controlled for a number of potential confounds, such as intentionality of weight loss, obesity status prior to weight loss, occult disease or pathology, and smoking status.

A small number of clinical trials have been conducted to examine the effects of weight-loss treatment among older, obese adults, ${ }^{21-23}$ but a recent meta-analysis suggested that high-quality evidence regarding the efficacy of weight-loss interventions among older adults is lacking and that additional studies are needed. ${ }^{23}$ This meta-analysis also indicated that although obese, older adults are able to achieve significant weight losses, changes in blood pressure, lipid profile, glycemic control, exercise capacity, and quality of life, as a consequence of weight-loss treatment, did not reach statistical significance. Moreover, data on these health outcomes were very limited, and there was substantial heterogeneity across studies. ${ }^{23}$ Adverse outcomes were not examined in this metaanalysis, though results from the Diabetes Prevention Program indicated that rates of musculoskeletal adverse events were slightly higher among the lifestyle intervention group as compared with the placebo (although authors reported no significant differences by treatment assignment). ${ }^{24}$ Older participants were more likely to report adverse events as compared with younger participants. ${ }^{24}$ In a recent randomized controlled clinical trial examining the effectiveness of diet, exercise, or a combination, among adults 65 years of age or older, Villareal et $\mathrm{al}^{22}$ reported that participants in the diet-only arm experienced reductions in lean body mass and bone mineral density, while participants in the exercise arm reported a greater degree of musculoskeletal injuries. This study also reported significant improvements in a variety of weight-related health outcomes. ${ }^{22}$ However, authors did not report whether these risks and benefits of weight-loss treatment differed by age.

At present, it remains unclear whether the benefits of intentional weight loss in older, obese adults outweigh potential risks of weight-loss treatment, and whether improvements in health or risks associated with treatment are similar across age cohorts. Few studies have examined the effects of behavioral weight-loss treatment in older adults. ${ }^{10,25}$ Intentional weight loss in older, obese adults could ameliorate weight-related diseases and conditions, such as joint pain, psychological symptoms, and quality of life, ${ }^{10}$ but could simultaneously present risks with regards to musculoskeletal injury, and bone and muscle loss.

The current study investigated both the health benefits (ie, weight loss, improvements in metabolic risk factors) and adverse consequences of weight-loss treatment in older adults (65-74 years) and examined whether these effects were comparable to those experienced by middle-aged adults (50-59 years). The primary aims of the present study were to determine: (1) if older, obese women experience significant benefits (ie, weight loss) from a lifestyle intervention for weight loss; (2) if behavioral weight-loss treatment is associated with negative outcomes (ie, musculoskeletal injury) for older, obese women; and (3) if weight loss and adverse event outcomes are equivalent in older and middle-aged participants. We hypothesized that positive and adverse outcomes would be similar across age groups. A secondary aim of this study was to describe and compare the responses of older and middle-aged participants with regards to changes in metabolic risk factors, including systolic blood pressure, LDL cholesterol, Hemoglobin $\mathrm{A}_{1 \mathrm{c}}$, and C-reactive protein.

\section{Materials and methods}

This study is a secondary analysis of data collected in the TOURS (Treatment of Obesity in Underserved Rural Settings) trial. TOURS was a randomized, controlled trial of behavioral weight-loss treatment, in six medically underserved rural counties in northern Florida, USA. ${ }^{26}$

\section{Participants}

Participants in the TOURS trial were 298 women (aged $50-75$ years), with body mass index (BMI) $>30 \mathrm{~kg} / \mathrm{m}^{2}$, who resided in rural counties in north-central Florida. Potential participants were excluded if they weighed over $158.8 \mathrm{~kg}$, had 
a history of heart attack or stroke, metabolic abnormalities, any musculoskeletal conditions that limited walking, any major psychiatric disorders, or experienced significant weight loss (ie, $\geq 4.5 \mathrm{~kg}$ ) in the 6 months prior to the study.

\section{Procedure}

The University of Florida Institutional Review Board approved all study procedures. Recruitment and study methods have been described previously. ${ }^{26}$ At months 0,6 , and 18 , participants' weights and blood pressures were assessed, and blood was drawn and analyzed for metabolic profile. Participant height was measured at month 0 but not during the later assessment points.

\section{Measures}

Primary aims

\section{Percent weight change}

Weight was measured to the nearest 0.1 kilogram using a calibrated and certified balance beam scale. Participants were measured in light indoor clothing with shoes removed. Change in body weight was calculated by subtracting participants' 6 and 18 month weights from their baseline values. Participant height was measured, without shoes, to the nearest $1.0 \mathrm{~cm}$ using a portable stadiometer. Height and weight were used to calculate BMI.

\section{Musculoskeletal adverse events}

Participants were asked to report all adverse events experienced throughout the duration of the study. Adverse events were categorized for review by a local Institutional Review Board and by a specially constituted Data Safety and Monitoring Board. Additionally, all events were separately recoded, as representing a musculoskeletal injury or other type of adverse event. Musculoskeletal adverse events were chosen because research has demonstrated a slight increase risk of this type of injury with lifestyle treatment. ${ }^{24}$

\section{Secondary aim}

\section{Metabolic risk factors}

Resting blood pressure was measured by a Registered Nurse (RN), using a standardized protocol. ${ }^{27}$ In the present study, only systolic blood pressure was examined due to its relation to cardiovascular disease risk. ${ }^{28}$ Similarly, lipid profile was measured using low density lipoprotein (LDL)-cholesterol due to its strong association with cardiovascular disease risk. ${ }^{29}$ Glycemic control, which is highly related to diabetic risk, ${ }^{30}$ was assessed via Hemoglobin $\mathrm{A}_{1 \mathrm{c}}\left(\mathrm{HbA}_{1 \mathrm{c}}\right)$, which is a more durable measure of glycemic control than fasting glucose. ${ }^{31}$
C-reactive protein is a marker of inflammation, which is associated with atherosclerosis and cardiovascular disease, and was also measured. ${ }^{32}$ Blood samples were drawn by the study RN and analyzed by Quest Diagnostics Clinical Laboratories (Quest Diagnostics Inc, Madison, NJ, USA) for lipid and metabolic profile.

\section{TOURS intervention}

All participants received a 6-month lifestyle intervention (Phase I) carried out through Cooperative Extension Service offices in six rural counties in North Florida. Phase I of the TOURS trial included 24 weekly group behavioral treatment sessions. The program was designed to decrease caloric intake (to $1200 \mathrm{kcal}$ per day) and increase moderate-intensity physical activity to reach a 10,000 per day step average or attain at least 3000 steps greater than baseline levels. No liquid meal supplements were utilized in the trial. At the conclusion of Phase I, these women were randomized to one of three year-long follow-up programs with biweekly contacts (Phase II): a face-to-face counseling program, a telephone counseling program, or a mail-only education "control" condition.

\section{Change in caloric intake and physical activity}

Change in caloric intake was assessed using the Block Food Frequency Questionnaire (Block FFQ). ${ }^{33}$ This self-report questionnaire asks participants to record the frequency at which they consumed 106 different foods over the preceding year. This questionnaire probes participants for the portion size of foods consumed, along with composition (eg, low- vs high-fat cuts of meat) and added condiments (eg, butter or jam added to toast). Estimates from the Block FFQ have been demonstrated to correlate 0.45 with estimated "true" dietary intake using 24-hour recalls. ${ }^{34}$

Physical activity was measured using the CHAMPS Physical activity questionnaire for older adults. ${ }^{35}$ This 40 -item questionnaire was specifically designed to assess types of physical activity that are appropriate for older adults. The CHAMPS has been validated against other physical activity measures, with correlations of 0.73 for moderateintensity activities (which were the focus of the current intervention), and 0.55 for all specified activities. ${ }^{35}$

\section{Statistical analyses}

The data analyses were performed using both a per-protocol and an intent-to-treat approach. All randomized participants were included in the intent-to-treat analyses. For this 
approach, multiple imputation was used to handle missing weights for individuals who dropped out after baseline; values were imputed assuming weight was regained back at a rate of $0.3 \mathrm{~kg}$ per month. ${ }^{36,37}$ The variance of this distribution was chosen as the variance of the residual from regressing 6-month (or 18-month) weights on baseline weight among those individuals without missing weights; this essentially corresponds to the variance under an assumption of missing at random (MAR). Use of this scenario is consistent with the findings from long-term studies of weight loss that show a reliable return to baseline weights over time and was used in the primary analysis of TOURS. ${ }^{26,38,39}$ For the metabolic risk factors, a similar multiple imputation approach was used, with means corresponding to the baseline value of the risk factor. For the equivalence tests, only treatment completers were used (a per-protocol approach). Use of only treatment completers is consistent with a recent Consolidated Standards of Reporting Trials (CONSORT) group statement regarding the appropriate use of equivalence testing. ${ }^{40}$ Use of intentto-treat analyses in equivalence testing can increase the risk of type I error, as it suppresses observed mean differences between groups. Statistical analyses were conducted using SPSS (v17.0 for Windows; IBM, Armonk, NY, USA) and SAS (v9.1.2 for Windows; SAS Institute Inc, Cary, NC, USA) software programs.

\section{Primary aims: weight loss and adverse events}

To determine if older, obese women experience significant benefits from a lifestyle intervention for weight loss, we fit multivariate normal regression models, controlling for race/ ethnicity, to examine changes in weight from month 0 to month 6 and month 18 using SAS Proc Mixed. Bonferroni corrections were applied to adjust for multiple comparisons.

To assess whether weight change and number of adverse events were equivalent between middle-aged and older obese women, we used equivalence tests. Margins of equivalence $(\Delta)$ for weight and the proportion of each group (older women and middle-aged women) reporting a musculoskeletal adverse event were set a priori, based on the smallest value that would represent a clinically significant difference. Weight outcomes for older and middle-aged participants were regarded as equivalent if the difference between group means (using a 95\% CI of the difference) was less than or equal to $2.5 \mathrm{~kg}$. Similarly, the proportions of each group reporting a musculoskeletal adverse event were regarded as equivalent if the $95 \% \mathrm{CI}$ of the difference was contained within $\pm \Delta$ $( \pm 0.04)$. The mean difference in weight change between older and middle-aged groups was obtained using multivariate normal regression. CIs of the difference in proportions of older and middle-aged women reporting a musculoskeletal adverse event were calculated using methods described by Newcombe. ${ }^{41}$

\section{Secondary aims: metabolic risk factors}

Multivariate normal regression models fit using SAS Proc Mixed were used to compare older and middle-aged participants with regards to changes in metabolic risk factors over time. Criterion variables included systolic blood pressure, LDL-cholesterol, $\mathrm{HbA}_{1 \mathrm{c}}$, and C-reactive protein. To adjust for multiple comparisons, Bonferroni corrections were applied.

\section{Results}

\section{Baseline characteristics by age}

The mean age of participants in the TOURS study was $59.3 \pm 6.2$ years. The present study included 56 older women (65-74 years) and 162 middle-aged women (50-59 years) drawn from the total sample. Among all 298 participants, $75.5 \%$ classified their race/ethnicity as Caucasian, $20.5 \%$ as African American, 1.7\% as Hispanic American, 2.0\% as American Indian, and $0.3 \%$ as Pacific Islander. The mean pretreatment weight was $96.5 \pm 14.9 \mathrm{~kg}$, and mean baseline BMI was $36.8 \pm 5.0 \mathrm{~kg} / \mathrm{m}^{2}$. The majority of the sample (64.4\%) had completed at least 12 years of education, with $43.3 \%$ reporting at least trade, vocational, or associate training. The majority of participants were married $(72.5 \%)$, and nearly half of the women were employed full or part time (47.3\%). Over two-thirds of the sample (67.9\%) reported a total household income of less than $\$ 50,000$.

Older women (ie, women 60-74 years; $\mathrm{n}=56$ ) in this study were more likely to be Caucasian, $\chi^{2}(1)=4.6, P<0.05$, and less likely to be employed, $\chi^{2}(1)=57.2, P<0.001$, than middle-aged women (ie, women 50-59 years; $n=162$ ). Older women weighed significantly less than middle-aged women at baseline, $\mathrm{t}(216)=2.3, P<0.025$, but this difference was not clinically significant, and both groups fell in the Class II obesity range (BMI 35.0 to $39.9 \mathrm{~kg} / \mathrm{m}^{2}$ ) at pretreatment. Older women did not differ from middle-aged women on any metabolic risk factor at pretreatment, with the exception of systolic blood pressure, which was higher in the older group, $\mathrm{t}(216)=-3.6, P<0.001$. Baseline characteristics by age are displayed in Table 1.

Previous analyses of the TOURS data have suggested that Caucasian women and African-American women respond differently to treatment in terms of magnitude of weight loss, changes in metabolic risk factors, and a 
Table I Baseline demographic characteristics of older and middle-aged participants

\begin{tabular}{|c|c|c|}
\hline & $\begin{array}{l}\text { Older (65-74 years) } \\
n=56\end{array}$ & $\begin{array}{l}\text { Middle-aged } \\
\text { (50-59 years) } \\
n=162\end{array}$ \\
\hline & Mean \pm SD & \\
\hline \multirow[t]{2}{*}{ Age (years) } & $69.1 \pm 2.9$ & $54.6 \pm 2.7$ \\
\hline & Percent of sample & \\
\hline \multicolumn{3}{|l|}{ Race/ethnicity (\%) } \\
\hline Caucasian & 83.9 & 69.1 \\
\hline African American & 12.5 & 25.9 \\
\hline \multicolumn{3}{|l|}{ Employment (\%) } \\
\hline Full or part time & 10.7 & 69.1 \\
\hline Retired & 55.4 & 5.6 \\
\hline Not working & 8.9 & 6.2 \\
\hline More than one category & 19.6 & 9.9 \\
\hline
\end{tabular}

Abbreviation: SD, standard deviation.

number of behavioral variables. ${ }^{42}$ The older age group was comprised of a significantly greater proportion of Caucasian women, thus equivalence testing was conducted separately for Caucasian and African American women. However, given that the older age group contained only seven African American women, we did not have enough power to perform formal tests of equivalence with this subsample. Thus, only descriptive statistics are provided.

\section{Weight change}

Using a per-protocol analysis (ie, treatment completers only) we fit a multivariate normal regression to examine within-group changes in weight, while controlling for race/ ethnicity. The proportion of older women who completed the study was not significantly different from the proportion of middle-aged women, $\chi^{2}(1)=0.58, P=0.466$. Similarly, there were no significant differences between the proportion of older and middle-aged women who returned for assessment at month 6 or month $18,(P=0.948$ and 0.467 , respectively). There were also no significant differences between groups in reported caloric change from month 0 to month 6 for older and middle-aged women $(-438.7 \mathrm{kcal} /$ day vs $-504.7 \mathrm{kcal} /$ day, $P=0.645)$, although both groups experienced significant decreases in reported caloric intake over this time, $\mathrm{t}(51)=4.5, P<0.0001$, and $\mathrm{t}(145)=6.5$, $P<0.0001$, respectively. With respect to changes in reported physical functioning, while both older and middleaged women significantly increased their average distance walked from month 0 to month 6 (65.9 feet vs 71.8 feet, $\mathrm{t}[50]=3.46, P<0.001$ and $\mathrm{t}[140]=5.39, P<0.0001$, respectively), there was no significant difference between groups in this change, $P=0.812$.
Older women evidenced a significant reduction in weight from month 0 to month 6 , mean \pm standard error $(\mathrm{SE})=$ $9.3 \pm 0.76 \mathrm{~kg}, P<0.001$. This weight loss was largely maintained at month 18 , at $7.6 \pm 1.3 \mathrm{~kg}, P<0.001$. Similarly, middleaged women experienced a significant within-group weight loss from month 0 to month 6 , mean $\pm \mathrm{SE}=10.1 \pm 0.68 \mathrm{~kg}$, and this loss was largely maintained at month 18 , mean $\pm \mathrm{SE}=7.6 \pm 0.86 \mathrm{~kg}$. Changes in weight over time among treatment completers are displayed in Table 2. Using an intent-to-treat approach produced similar results (Figure 1).

With respect to clinically significant weight loss (ie, weight loss $\geq 5 \%$ of baseline weight), there were no further differences by age group over time. At 6 months, $78.8 \%$ of older adults achieved a $\geq 5 \%$ weight loss compared with $75.0 \%$ of middle-aged adults, $\chi^{2}(1)=0.312, P=0.576$; at 18 months, $57.1 \%$ of older women maintained a clinically significant weight loss compared with $51.1 \%$ of middle-aged women, $\chi^{2}(1)=0.530, P=0.467$.

\section{Equivalence testing Weight change}

Among treatment completers, older Caucasian women $(\mathrm{n}=47)$ lost a mean $\pm \mathrm{SE}$ of $9.6 \pm 0.83 \mathrm{~kg}$ from month 0

Table 2 Changes in weight and metabolic risk factors in older and middle-aged women (per-protocol analysis)

\begin{tabular}{|c|c|c|}
\hline & \multicolumn{2}{|l|}{ Mean \pm SE } \\
\hline & $\begin{array}{l}\text { Older } \\
\text { (65-74 years) }\end{array}$ & $\begin{array}{l}\text { Middle-aged } \\
\text { (50-59 years) }\end{array}$ \\
\hline \multicolumn{3}{|c|}{ Weight (kg) } \\
\hline Month 0 & $92.7 \pm 2.4$ & $97.0 \pm 1.2$ \\
\hline Month 6 & $83.4 \pm 2.5$ & $86.9 \pm 1.2$ \\
\hline Month 18 & $85.1 \pm 2.7^{a}$ & $89.4 \pm 1.3^{\mathrm{a}}$ \\
\hline \multicolumn{3}{|c|}{ Systolic BP (mm Hg) } \\
\hline Month 0 & $129.6 \pm 1.2$ & $124.3 \pm 0.9$ \\
\hline Month 6 & $122.3 \pm 1.5$ & $I I 6 . I \pm 1.0$ \\
\hline Month 18 & $124.0 \pm 2.0^{\mathrm{a}}$ & $118.9 \pm 1.2^{\mathrm{a}}$ \\
\hline \multicolumn{3}{|c|}{ LDL-cholesterol (mg/dL) } \\
\hline Month 0 & $115.8 \pm 4.2$ & $123.7 \pm 2.8$ \\
\hline Month 6 & $122.3 \pm 1.5$ & $116.1 \pm 1.0$ \\
\hline Month 18 & $119.5 \pm 6.0$ & $122.5 \pm 3.1$ \\
\hline \multicolumn{3}{|c|}{$\mathrm{HbA}_{\mathrm{Ic}}(\%)$} \\
\hline Month 0 & $6.1 \pm 0.1$ & $5.9 \pm 0.1$ \\
\hline Month 6 & $5.8 \pm 0.1$ & $5.7 \pm 0.1$ \\
\hline Month 18 & $5.9 \pm 0.1^{\mathrm{a}}$ & $5.8 \pm 0.1^{\mathrm{a}}$ \\
\hline \multicolumn{3}{|c|}{ C-reactive protein (mg/dL) } \\
\hline Month 0 & $4.4 \pm 0.8$ & $6.5 \pm 0.5$ \\
\hline Month 6 & $2.3 \pm 0.3$ & $3.9 \pm 0.3$ \\
\hline Month 18 & $2.5 \pm 0.4^{a}$ & $3.7 \pm 0.4^{\mathrm{a}}$ \\
\hline
\end{tabular}

Notes: Indicates significant within-group differences, $P<0.01$.

Abbreviations: $B P$, blood pressure; $L D L$, low density lipoprotein; $\mathrm{HbA}_{\mathrm{lc}}$, hemoglobin $\mathrm{A}_{\mathrm{Ic}}$; $\mathrm{SE}$, standard error. 


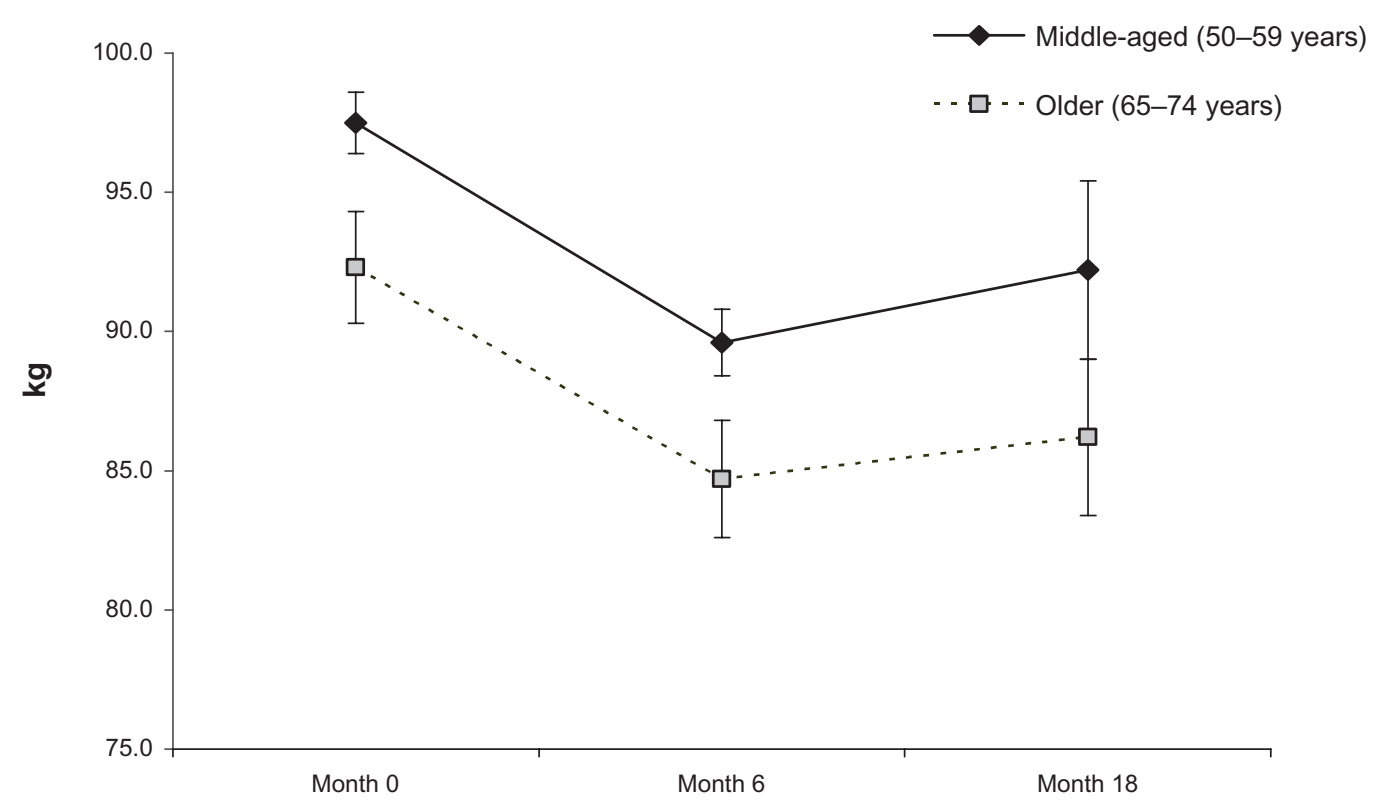

Figure I Change in weight over time, adjusted for race/ethnicity (intent-to-treat analysis).

to month 6 , which was not significantly different from the $11.0 \pm 0.55 \mathrm{~kg}$ weight loss achieved by middle-aged Caucasian women $(\mathrm{n}=112)$. The $95 \% \mathrm{CI}$ of the difference $(-3.4$ to $0.55)$ was not contained within the margin of equivalence $(2.5 \mathrm{~kg})$, thus, statistical equivalence could not be established. At long-term follow up, older women had lost a mean of $7.6 \pm 1.3 \mathrm{~kg}$ body weight; again, this was not significantly different from the $7.4 \pm 0.76 \mathrm{~kg}$ weight loss evidenced by middle-aged women. The groups were not equivalent with respect to weight loss at month 18 , as the $95 \%$ CI of the difference exceeded the margin of equivalence (95\% CI: -2.8 to 3.2 , respectively).

Older African American women $(n=7)$ lost a mean of $5.9 \pm 3.0 \mathrm{~kg}$ of body weight from month 0 to month 6 , as compared with $6.7 \pm 4.3 \mathrm{~kg}$ for the middle-aged African American women $(n=42)$. At long-term follow-up, older African American women had lost $6.1 \pm 5.1 \mathrm{~kg}$ of body weight as compared with $5.0 \pm 7.7 \mathrm{~kg}$ for the middle-aged women.

\section{Adverse events}

Point-biserial correlations indicated that there was no relationship between age (as a continuous variable) and the report of injury at 6 or 18 months $(\mathrm{r}=0.05, P=0.400$, and $\mathrm{r}=0.03, P=0.630$, respectively). During initial treatment (month 0 to 6 ), 23\% of older Caucasian women reported at least one musculoskeletal adverse event, as compared with $18 \%$ of middle-aged Caucasian women. The $95 \% \mathrm{CI}$ of the difference in proportions, calculated according to the methods described by Newcombe, ${ }^{41}$ was $-20.6 \%$ to $7.2 \%$, well outside the margin of equivalence (4\%). The proportion of older women reporting a musculoskeletal adverse event over the course of the entire study (month 0 to 18 ) was $47 \%$, as compared with $36 \%$ of middle-aged Caucasian women, $\chi^{2}(1)=1.7, P=0.19$. Again, the $95 \%$ CI of the difference in proportions fell outside the margin of equivalence $(95 \% \mathrm{CI}$ : -27.3 to 5.2 ).

To further investigate the risk of musculoskeletal injury, we divided all participants into ad hoc 5-year age cohorts. Although the sample of women over 70 years of age was not large enough to conduct a formal significance test $(n=16)$, $56 \%$ of Caucasian participants over 70 years of age reported at least one adverse event over the course of the study as compared with $37 \%$ of Caucasian women ages 50 to 69 years ( $\mathrm{n}=209)$.

During initial treatment, $11 \%$ of older African-American women reported a musculoskeletal adverse event, as compared with $26 \%$ of middle-aged women. At long-term follow up, $42 \%$ of middle-aged African-American women had reported at least one adverse event, as compared with only $11 \%$ of older African-American women. There was a trend for older African-American women to be less likely to report a musculoskeletal adverse event overall than middle-aged African-American women, $\chi^{2}(1)=3.1, P=0.078$, again a difference that may have reached significance with a larger sample size.

\section{Secondary aims: metabolic risk factors}

Using a per-protocol approach, older women experienced significant reductions in systolic blood pressure from month 0 to month 6 , mean $\pm \mathrm{SE}=7.3 \pm 1.77, P<0.001$, and maintained 
these improvements at month 18 , mean change \pm SE month 0 to $18=5.9 \pm 1.8, P<0.01$. Changes in LDL cholesterol were not significant over time. $\mathrm{HbA}_{1 \mathrm{c}}$ was significantly reduced from month 0 to months $6,0.32 \pm 0.01, P<0.001$; and from month 0 to month $18,0.25 \pm 0.09, P<0.01$. C-reactive protein was also significantly reduced from month 0 to month 6 , $2.1 \pm 0.63, P<0.001$; these changes were maintained at month $18,-2.0 \pm 0.70, P<0.01$. Changes in metabolic risk factors over time can be seen in Table 2. Using an intent-to-treat approach, a similar pattern of results emerged (Figure 2).

\section{Discussion}

The present study examined both the benefits (ie, weight loss and improvements in metabolic risk factors) and adverse outcomes of a lifestyle intervention for weight loss in a sample of older and middle-aged adults, and compared these outcomes between age groups. Older women achieved significant reductions in weight during treatment and at long-term follow up. Among treatment completers, older Caucasian women had lost a mean of $9.6 \mathrm{~kg}$ of body weight at 6 months, which was not statistically different from the $11.0 \mathrm{~kg}$ of weight loss achieved by middle-aged Caucasian women. At 18 months, the difference between older and middle-aged participants

\section{Systolic blood pressure}
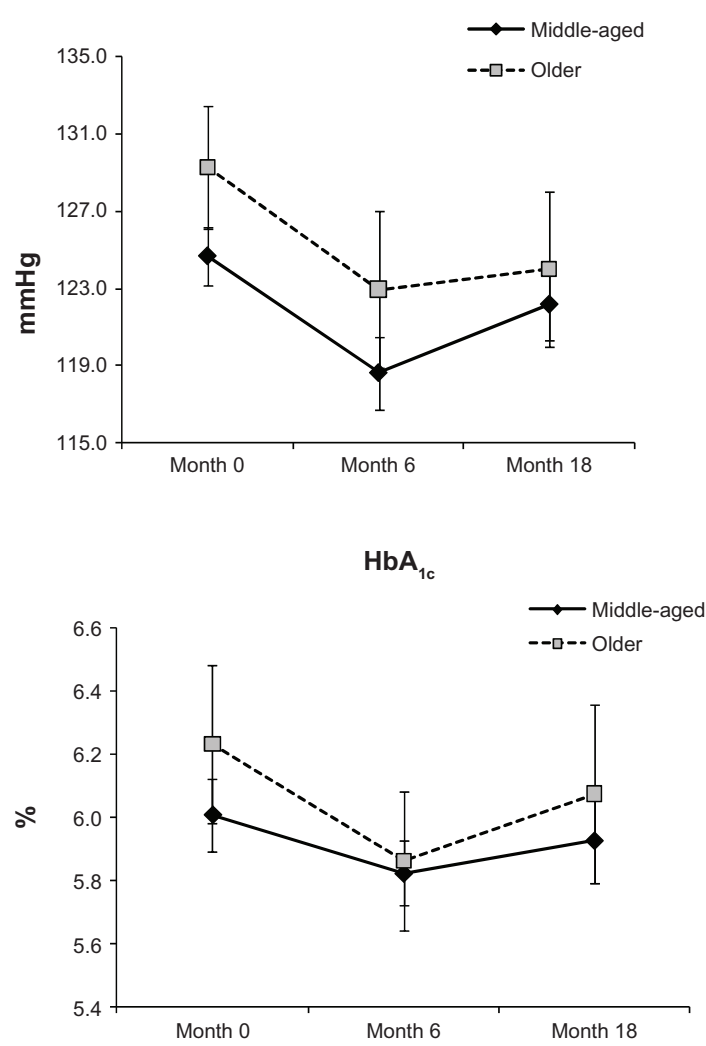

exceeded the margin of equivalence (7.5 vs $8.5 \mathrm{~kg}$; 95\% CI: -2.4 to 4.4 ), possibly due to the small sample size of older adults. A comparison of middle-aged and older AfricanAmerican women revealed a trend for older women to lose more weight than middle-aged women from baseline to month 18 (6.1 kg of body weight as compared with $5.0 \mathrm{~kg}$ ).

With regards to adverse outcomes, $23 \%$ of older Caucasian women reported at least one musculoskeletal injury during initial treatment, and $47 \%$ reported this type of adverse event over the course of the 18-month intervention. These proportions were not significantly different from the $18 \%$ of middle-aged women reporting an injury during initial treatment and the $36 \%$ reporting an injury throughout the 18 month study. The Diabetes Prevention Program Research Group described a similar pattern of results for participants in the "lifestyle" condition, by which participants between 60 and 85 years of age reported 28 musculoskeletal adverse events per 100 person-years, in contrast to 25 to 40 year old participants, who reported 20 musculoskeletal adverse events per 100 person-years, a nonsignificant difference. ${ }^{24}$

The proportions of middle-aged and older women reporting a musculoskeletal adverse event during initial treatment and over the course of the entire study were not equivalent.
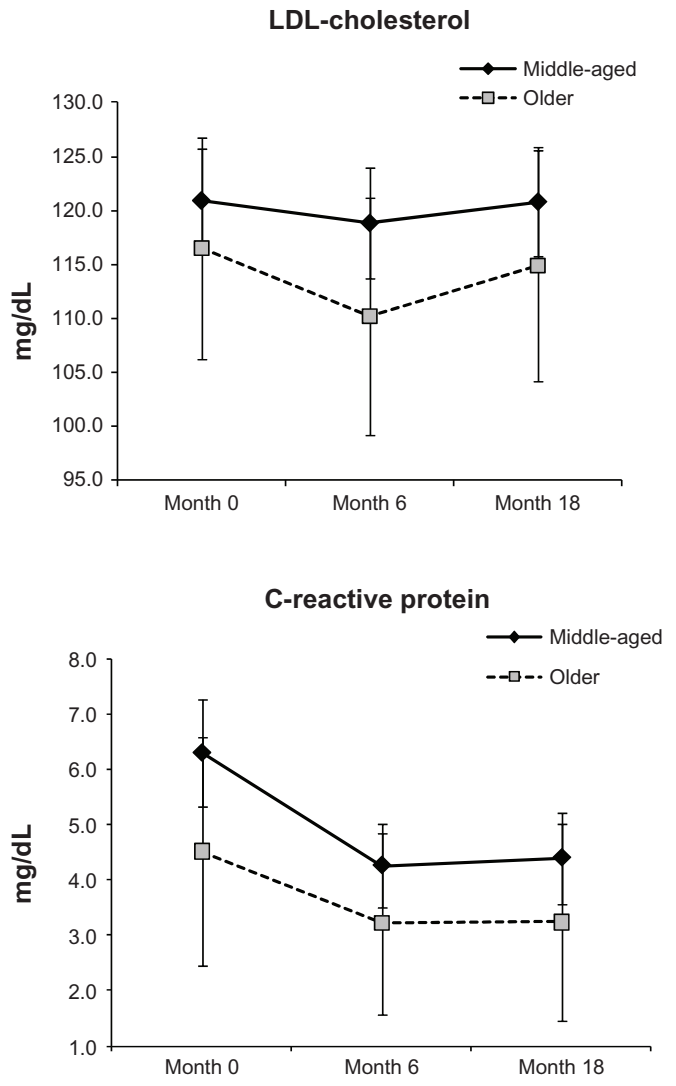

Figure 2 Changes in risk factors over time, adjusted for race/ethnicity (intent-to-treat analysis). Abbreviations: $L D L$, low density lipoprotein; $\mathrm{HbA}_{\mathrm{Ic}}$, hemoglobin $\mathrm{A}_{\mathrm{Ic}}$. 
Post hoc power analyses suggested we would have needed over 800 participants per group to determine equivalence, even if we had used a wider 10\% margin. Beyond rejecting our hypothesis that older and middle-aged women experience comparable rates of injury, it appears that older Caucasian women may be at greater risk for injury than middle-aged Caucasian women. When we further categorized the sample into 5-year age increments, $56 \%$ of Caucasian women over 70 years of age reported at least one musculoskeletal injury throughout the 18 months, as compared with only $37 \%$ of Caucasian participants 50 to 69 years of age. Given that only 16 women fell into the above 70 -year age range, we did not have enough power to examine differences in the proportion of women over 70 reporting a musculoskeletal injury, as compared with younger age groups. This discrepancy warrants further investigation regarding the safety of behavioral weight-loss treatment for older adults, with a larger sample. A related finding deserving of further investigation is the potential trend for older African-American women to report fewer adverse events than their younger counterparts. Future research with larger samples of racial and ethnic subpopulations should examine these potential differences.

With respect to our secondary aims, older women experienced a significant reduction in systolic blood pressure from pre- to posttreatment and largely maintained this decrease at 18 months. Additionally, older women showed significant reductions in $\mathrm{HbA}_{1 \mathrm{c}}$ and $\mathrm{C}$-reactive protein from month 0 to month 6 , and from month 0 to month 18 . There was no significant within-group change over time in LDL-cholesterol levels. Overall, the current results support the hypothesis that older women experience a number of benefits from lifestyle interventions for weight loss. However, the present study did not measure additional health-related parameters, such as medication use or changes in body composition, muscular strength, or physical functioning. While outcomes from weight loss in older adults hold both potential risks and benefits, ${ }^{43}$ further investigation of these variables is warranted.

There are several limitations to the present study. First, we had a relatively small sample of older women, offering limited power to detect small differences in a variety of outcomes. A second limitation was the lack of an untreated control group of older women. Although there appeared to be a slight increase in risk of musculoskeletal injury for older women, we cannot determine if this increase was related to participation in the study or the consequence of aging. Future research should compare the rate of musculoskeletal injury in older women not undergoing weight-loss treatment with those participating in the lifestyle program, to clarify if this type of treatment is associated with greater risk of injury in older adults.

Additionally, individuals with serious health conditions (eg, uncontrolled diabetes or hypertension) were excluded from the study. Given that the severity of weight-related risk factors and diseases is typically compounded with age, the exclusion of older women with serious health conditions at baseline may have resulted in a sample that is not representative of the larger population of women over 65 years of age. Generalizability is also limited by the exclusion of younger age groups as well as the underrepresentation of older racial/ ethnic minority participants.

This study has several important implications with regards to the safety and efficacy of behavioral weight-loss interventions for older adults. We found that older women (those over 65 years of age) experienced significant benefits from a lifestyle intervention for weight loss. However, results also indicated that older women might be at greater risk for musculoskeletal adverse events during participation in a lifestyle intervention for weight loss as compared with their middleaged counterparts. Subsequently, lifestyle interventions including older adults should take particular precautions to educate participants about safe ways to achieve exercise goals and avoid injury (eg, including several supervised exercise sessions at initiation of treatment). Future research should further explore potential negative outcomes of weight-loss treatment for older, obese adults, particularly with respect to musculoskeletal injury, and bone and muscle loss.

\section{Acknowledgment}

This research was supported by grant R18HL 73326 from the National Heart, Lung and Blood Institute. Publication of this article was funded in part by the University of Florida Open Access Publishing Fund.

\section{Disclosure}

The authors report no conflicts of interest in this work.

\section{References}

1. Flegal KM, Carroll MD, Kit BK, Ogden CL. Prevalence of obesity and trends in the distribution of body mass index among US adults, 1999-2010. JAMA. 2012;307(5):491-497.

2. Must A, Spadano J, Coakley EH, Field AE, Colditz G, Dietz WH. The disease burden associated with overweight and obesity. JAMA. 1999;282(16):1523-1529.

3. Corrada MM, Kawas CH, Mozaffar F, Paganini-Hill A. Association of body mass index and weight change with all-cause mortality in the elderly. Am J Epidemiol. 2006;163(10):938-949.

4. Flegal KM, Graubard BI, Williamson DF, Gail MH. Excess deaths associated with underweight, overweight, and obesity. JAMA. 2005;293(15):1861-1867. 
5. Locher JL, Roth DL, Ritchie CS, et al. Body mass index, weight loss, and mortality in community-dwelling older adults. J Geront A Biol Sci Med Sci. 2007;62(12):1389-1392.

6. Manson JE, Willett WC, Stampfer MJ, et al. Body weight and mortality among women. $N$ Engl J Med. 1995;333(11):677-685.

7. Villareal DT, Apovian CM, Kushner RF, Klein S; for the American Society for Nutrition; NAASO, The Obesity Society. Obesity in older adults: technical review and position statement of the American Society for Nutrition and NAASO, The Obesity Society. Am J Clin Nutr. 2005 82(5):923-934.

8. Villareal DT, Banks M, Siener C, Sinacore DR, Klein S. Physical frailty and body composition in obese elderly men and women. Obes Res. 2004;12(6):913-920.

9. Felson DT, Zhang Y, Hannan MT, Anderson JJ. Effects of weight and body mass index on bone mineral density in men and women: the Framingham study. J Bone Miner Res. 1993;8(5):567-573.

10. Rössner S. Obesity in the elderly-a future matter of concern? Obes Rev. 2001;2(3):183-188.

11. Lavie CJ, Milani RV, Ventura HO. Obesity and cardiovascular disease: risk factor, paradox, and impact of weight loss. J Am Coll Cardiol. 2009;53(21):1925-1932.

12. Uretsky S, Messerli FH, Bangalore S, et al. Obesity paradox in patients with hypertension and coronary artery disease. Am J Med. 2007;120(10):863-870.

13. Jeffery RW, Drewnowski A, Epstein LH, et al. Long-term maintenance of weight loss: current status. Health Psychol. 2000; 19(Suppl 1):S5-S16.

14. Wadden TA, Crerand CE, Brock J. Behavioral treatment of obesity. Psychiatr Clin North Am. 2005;28(1):151-170.

15. Perri MG, Fuller PR. Success and failure in the treatment of obesity: Where do we go from here? Med Exer Nutr Health. 1995;4:255-272.

16. National Institutes of Health. Clinical guidelines on the identification, evaluation, and treatment of overweight and obesity in adults - The Evidence Report. Obes Res. 1998;6 Suppl 2:S51-S209.

17. Wing RR, Venditti E, Jakicic JM, Polley BA, Lang W. Lifestyle intervention in overweight individuals with a family history of diabetes. Diabetes Care. 1998;21(3):350-359.

18. Maggio CA, Pi-Sunyer FX. The prevention and treatment of obesity: Application to type 2 diabetes. Diabetes Care. 1997;20(11):1744-1766.

19. Thomas DR. Weight loss in older adults. Rev Endocr Metab Disord. 2005;6(2):129-136.

20. Wallace JI, Schwartz RS. Epidemiology of weight loss in humans with special reference to wasting in the elderly. Int J Cardiol. 2002; 85(1):15-21.

21. Bales CW, Buhr G. Is obesity bad for older persons? A systematic review of the pros and cons of weight reduction in later life. $J \mathrm{Am} \mathrm{Med}$ Dir Assoc. 2008;9(5):302-312.

22. Villareal DT, Chode S, Parimi N, et al. Weight loss, exercise, or both and physical function in obese older adults. $N$ Engl J Med 2011;364(13):1218-1229.

23. Witham MD, Avenell A. Interventions to achieve long-term weight loss in obese older people: a systematic review and meta-analysis. Age Ageing. 2010;39(2):176-184.

24. Diabetes Prevention Program Research Group; Crandall J, Schade D, Ma Y, et al. The influence of age and the effects of lifestyle modification and metformin in prevention of diabetes. J Gerontol. 2006;61(10):1075-1081.

25. Zamboni M, Mazzali G, Zoico E, et al. Health consequences of obesity in the elderly: a review of four unresolved questions. Int J Obes (Lond). 2005;29(9):1011-1029.

26. Perri MG, Limacher MC, Durning PE, et al. Extended-care programs for weight management in rural communities: the treatment of obesity in underserved rural settings (TOURS) randomized trial. Arch Intern Med. 2008;168(21):2347-2354.
27. Chobanian AV, Bakris GL, Black HR, et al; for the Joint National Committee on Prevention, Detection, Evaluation, and Treatment of High Blood Pressure; National Heart, Lung, and Blood Institute:National High Blood Pressure Education Program Coordinating Committee. Seventh report of the Joint National Committee on Prevention, Detection, Evaluation, and Treatment of High Blood Pressure. Hypertension. 2003;42(6):1206-1252.

28. Prospective Studies Collaboration. Age-specific relevance of usual blood pressure to vascular mortality: a meta-analysis of individual data for one million adults in 61 prospective studies. Lancet. 2002;360(9349):1903-1913

29. Expert Panel on Detection, Evaluation, and Treatment of High Blood Cholesterol in Adults. Executive summary of the third report of the National Cholesterol Education Program (NCEP) Expert panel on detection, evaluation, and treatment of high blood cholesterol in adults (Adult Treatment Panel III). JAMA. 2001;285(19): 2486-2497.

30. American Diabetes Association. Implications of the United Kingdom Prospective Diabetes Study. Diabetes Care. 2002;25 Suppl 1: S27-S31.

31. Centers for Disease Control and Prevention. Team Care: Comprehensive Lifetime Management for Diabetes. Atlanta: Centers for Disease Control and Prevention, National Center for Chronic Disease Prevention and Health Promotion; 2001.

32. Libby P, Ridker PM, Maseri A. Inflammation and atherosclerosis. Circulation. 2002;105(9):1135-1143.

33. Block G, Hartman AM, Dresser CM, Carroll MD, Gannon J, Gardner L. A data-based approach to diet questionnaire design and testing. Am J Epidemiol. 1986;124(3):453-469.

34. Subar AF, Thompson FE, Kipnis V, et al. Comparative validation of the Block, Willet, and National Cancer Institute Food Frequency Questionnaires: the Eating at America's Table Study. Am J Epidemiol. 2001;154(12):1089-1099.

35. Stewart AL, Mills KM, King AC, Haskell WL, Gillis D, Ritter PL. CHAMPS physical activity questionnaire for older adults: outcomes for interventions. Med Sci Sports Exerc. 2001;33(7):1126-1141.

36. Wadden TA, Berkowitz RI, Womble LG, et al. Randomized trial of lifestyle modification and pharmacotherapy for obesity. $N$ Engl $J$ Med. 2005;353(20):2111-2120.

37. Wing RR, Tate DF, Gorin AA, Ravnor HA, Fava JL. A selfregulation program for maintenance of weight loss. New Engl J Med. 2006;355(15):1563-1571.

38. Kramer FM, Jeffery RW, Forster JL, Snell MK. Long-term follow-up of behavioral treatment for obesity: patterns of weight regain among men and women. Int J Obes. 1989;13(2):123-136.

39. Stalonas PM, Perri MG, Kerzner AB. Do behavioral treatments of obesity last? A five-year follow-up investigation. Addict Behav. 1984;9(2):175-183.

40. Piaggio G, Elbourne DR, Altman DG, Pocock SJ, Evans SJ; for the CONSORT Group. Reporting of noninferiority and equivalence randomized trials: an extension of the CONSORT statement. JAMA. 2006;295(10):1152-1160.

41. Newcombe RG. Two-sided confidence intervals for the single proportion: comparison of seven methods. Stat Med. 1998;17(8):857-872.

42. Rickel KA, Milsom VA, Ross KM, Hoover VJ, Peterson ND, Perri MG. Differential response of African American and Caucasian women to extended-care programs for obesity management. Ethn Dis. Spring 2011;21(2):170-175.

43. Houston DK, Nicklas BJ, Zizza CA. Weighty concerns: the growing prevalence of obesity among older adults. J Am Diet Assoc. 2009;109(11):1886-1895. 


\section{Publish your work in this journal}

Clinical Interventions in Aging is an international, peer-reviewed journal focusing on evidence-based reports on the value or lack thereof of treatments intended to prevent or delay the onset of maladaptive correlates of aging in human beings. This journal is indexed on PubMed Central, MedLine, the American Chemical Society's 'Chemical Abstracts Ser-

vice' (CAS), Scopus and the Elsevier Bibliographic databases. The manuscript management system is completely online and includes a very quick and fair peer-review system, which is all easy to use. Visit $\mathrm{http} / / / \mathrm{www}$.dovepress.com/testimonials.php to read real quotes from published authors.

Submit your manuscript here: http://www.dovepress.com/clinical-interventions-in-aging-journal 